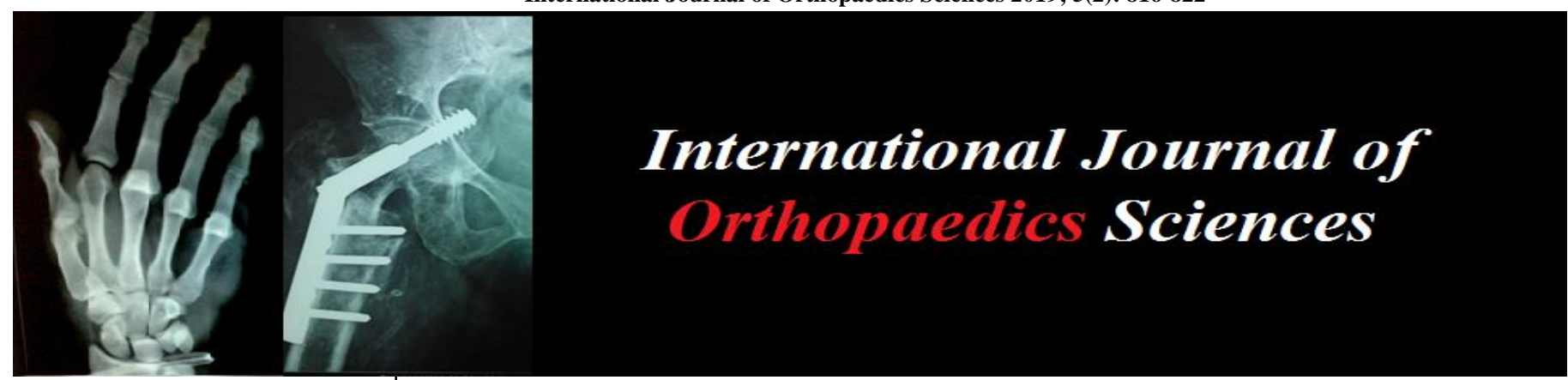

ISSN: $2395-1958$

IJOS 2019; 5(2): 816-822

(C) 2019 IJOS

www.orthopaper.com

Received: 14-02-2019

Accepted: 18-03-2019

Dr. Rohil Singh Kakkar Postgraduate Resident, Department of Orthopaedics, Ruby Hall Clinic, Pune, Maharashtra, India

\section{Principles and fundamental concepts in the fixation of proximal humerus fractures through a locking plate}

\author{
Dr. Rohil Singh Kakkar
}

DOI: https://doi.org/10.22271/ortho.2019.v5.i21.96

\section{Abstract}

Background: Proximal humerus fractures account for $5 \%$ of all fractures, with an incidence rate of 63 cases per thousand adult individuals per year.

They are often considerably displaced and communited in the elderly. About $75 \%$ of these fractures occur in patient above the age of 60 years. The female to male ratio is about 3:1 and the incidence of this fracture increases with age. It is in these older patients, that the mechanism of injury is usually a low energy trauma. As majority of these fractures occur in the osteoporotic bone, the operative treatment with Philos plate has of now become the gold standard.

Methods: A literature review of peer - reviewed publications related to the evaluation and management of proximal humerus fractures was performed. There was a focus on randomized controlled trials and an exploratory search in the Medline, PubMed, Embase database using the keywords "Proximal Humeral Fractures, locking plate, Philos, Delto- Pectoral approach was conducted.

Keywords: Philos, locking plate, proximal humerus fracture, calcar screw

\section{Introduction}

Proximal humerus fractures account for $5 \%$ of all fractures, with an incidence rate of 63 cases per thousand adult individuals per year.

These fractures have rising incidence late in life and this is directly related to osteoporosis. About $75 \%$ of these fractures occur in patient above the age of 60 years and the female to male ratio is 3:1. Treatment decisions are based on the mechanism of injury, the patients health, level of activity and the fracture pattern. The outcome of these fractures depends on various factors such as patient compliance, medical comorbidities, problems of neglect and surgical expertise. In contrast, patients with fractures fulfilling the criteria of instability, referred to as displaced or unstable fractures, benefit from surgical intervention which mostly renders reliable results, both clinically and radiographically ${ }^{[2,3]}$. The introduction of locking plate systems represents a milestone in fracture treatment with the advantage of improved osseous anchorage and higher resistance to failure by combining axial and angular stability [11, ${ }^{12]}$. Additionally, locking plates do not depend on friction or compression between plate and bone to stabilize the fracture and therefore do not compromise periosteal blood supply ${ }^{[13,14]}$. In proximal humeral fractures, the particular proximity of tendinous and neurovascular structures of the joint and the characteristic bone strength distribution of the humeral head require a fixation system with predetermined screw placement. The Philos plate system (Synthes, Oberdorf, Switzerland) was developed to meet these requirements by using a threedimensionally-fashioned locking system for the proximal screws. The insertion of multiple polyaxial locking screws through the specific targeting device into humeral head fragment provides a fixed angle support in multiple planes, which maintains the achieved reduction, while allowing for early mobilization ${ }^{[11]}$.

\section{Understanding the applied anatomy}

The primary deforming forces are the pectoralis and rotator cuff. The pectoralis major is inserted below the lesser tuberosity and pull the shaft anterior and medial. Greater tuberosity is attached by supraspinatus, infraspinatus and teres minor and when this is fractured, the fragments are displaced superiorly and posteriorly.
Dr. Rohil Singh Kakkar
Postgraduate Resident, Department of Orthopaedics, Ruby Hall Clinic, Pune, Maharashtra, India 
The lesser tuberosity is attached by subscapularis and this displaces the fragment medially. In case of surgical neck fractures, the proximal fragment is externally rotated and the distal fragment is displaced upward by the deltoid and medially by the pectoralis major. The glenohumeral joint is stabilized by the articular cartilage, labrum, ligaments, rotator cuff, and deltoid. Most humeral heads have a diameter between 4 and $5 \mathrm{~cm}$, and the head is slightly offset medially and posteriorly in relation to the humeral shaft ${ }^{[9]}$. The pectoralis major tendon inserts 5 to $6 \mathrm{~cm}$ from the top of the humeral head, which is a reliable tool for estimating implant stem length in severe fractures without landmarks.

Humeral shortening greater than $1 \mathrm{~cm}$ can impair deltoid function, whereas humeral lengthening and retroversion can impair tuberosity healing ${ }^{[10]}$. The proximal humeral blood supply is from the anterior and posterior humeral circumflex branches of the axillary artery, which are closely associated with the surgical neck and medial calcar (Figure 2). The arcuate artery is the terminal, ascending branch of the anterior humeral circumflex artery and enters the humeral head near the anatomic neck ${ }^{[6,11]}$. Fractures with short calcar fragments $(<8 \mathrm{~mm})$, a disrupted medial hinge, and anatomic neck involvement are most prone to ischemia ${ }^{[12]}$.

Gross axillary artery injury is exceedingly rare; however, in cases of significant shoulder trauma with a loss of Doppler signals and an enlarging axillary mass, vascular surgery should be consulted.

The most commonly injured nerves in descending order are the axillary, suprascapular, radial, musculocutaneous, median, and ulnar nerves. These are most commonly traction injuries that fully recover ${ }^{[14]}$. During surgery, the axillary nerve can be difficult to identify, particularly in scarred shoulders. It is about 4.5 to $7 \mathrm{~cm}$ from the proximal humerus and 0.5 to $4 \mathrm{~cm}$ from the surgical neck traveling through the quadrilateral space with the posterior humeral circumflex artery ${ }^{[15]}$. Care should be taken with incisions greater than $5 \mathrm{~cm}$ in length distal to the acromion. With anterolateral plating, the axillary nerve is most frequently in danger when placing screws near

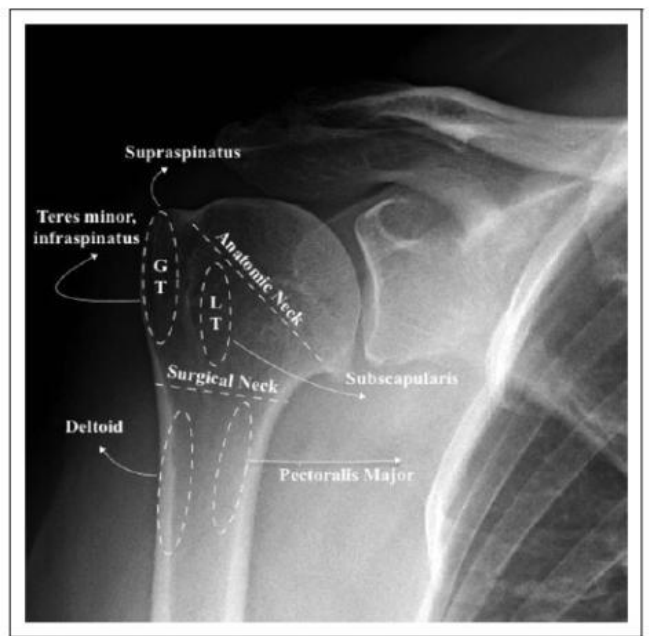

Figure I. Anteroposterior view of the shoulder demonstrating tendinous attachments to the proximal humerus and the associated direction of fragment displacement. GT denotes greater tuberosity: LT, lesser tuberosity.

\section{The neer's classification}

This classification is based on 4 fracture parts:

1. The greater tuberosity,

2. The lesser tuberosity,

3. The humeral head and the surgical neck through the middle segment of the plate. This is essential to understand in treating the patients by means of ORIF (Open reduction and internal fixation) as well as CRIF (Closed reduction and internal fixation) ${ }^{[16]}$.

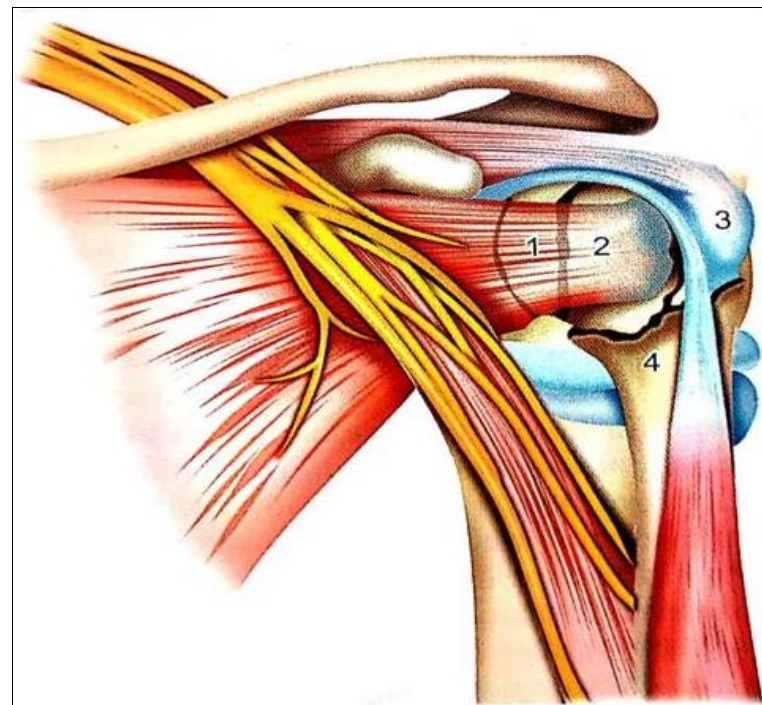

Fig 1. The Deforming Muscular Forces

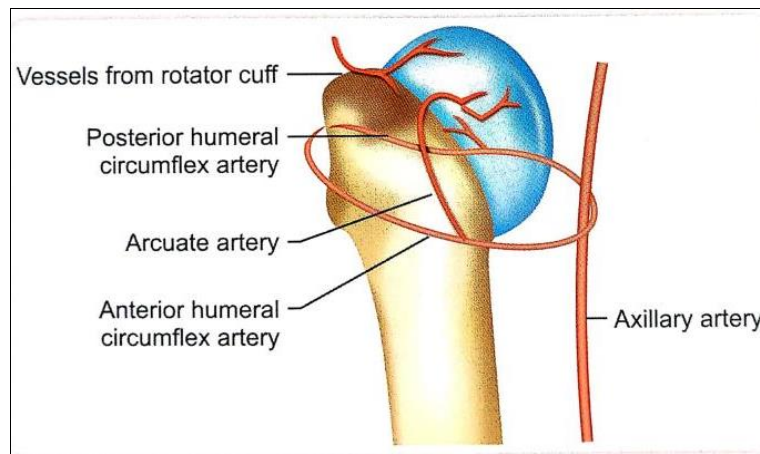

Fig. 2 Vascular anatomy of proximal humerus

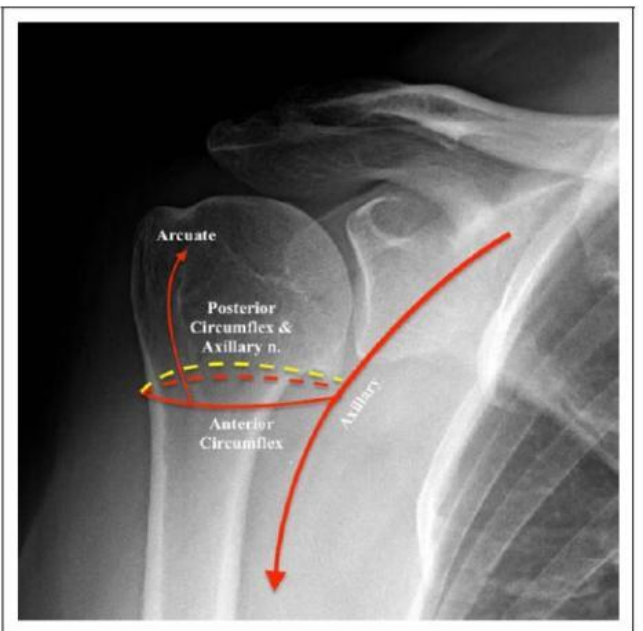

Figure 2. Anteroposterior view of the shoulder illustrating the vascular supply to the proximal humerus. The arcuate artery is a branch of the anterior humeral circumflex artery and ascends along the intertubercular groove before entering the humeral head. The posterior humeral circumflex artery travels with the axillary nerve.

4. The humeral shaft

For practical purposes, fractures are discussed based on the number of parts involved.

A fragment is considered to be displaced if it is separated more than $1 \mathrm{~cm}$ 


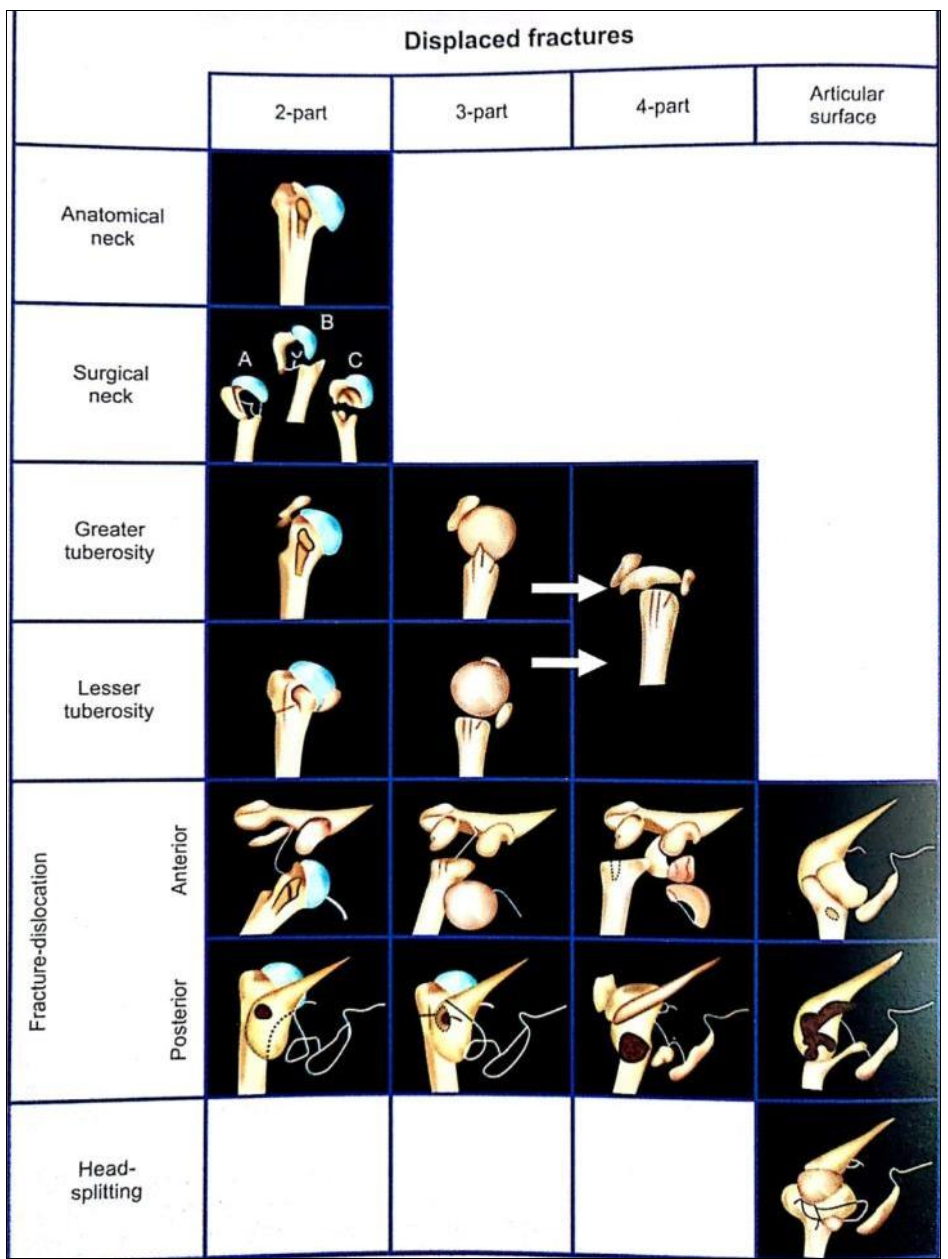

\section{Radiological evaluation and general considerations}

Important historical elements include the patient's level of ambulation, functional demands, and any pre-existing rotator cuff conditions. Evaluation should begin with inspection of the soft tissues and skin, as elderly patients are susceptible to poor wound healing. A full neurologic examination can be difficult following trauma, but function of the fingers, wrist, and elbow can often be evaluated. Axillary nerve innervation of the deltoid needs to be tested as reverse shoulder arthroplasty (RTSA) is a viable treatment option that requires an intact and innervated deltoid. True anteroposterior (AP), lateral, and axillary X-rays of the glenohumeral joint should be demanded. Computed tomography is recommended for complex fracture patterns or when fracture lines cannot be clearly visualized on the xrays. Magnetic resonance imaging (MRI) may be useful for assessing rotator cuff integrity when considering nonoperative treatment. In a prospective study of 30 patients, nearly $40 \%$ of proximal humerus fractures were associated with rotator cuff tears. 18

Bone density is a predictor of surgical reduction quality and screw cutout. 21, 22 Density can be assessed with cortical bone thickness measurements on AP views of the shoulder. Two techniques are detailed in Figure 4: the Tingart measurement and the deltoid tuberosity index. Bone quality and social independence can serve as indicators of physiologic age, which is more important than chronologic age when weighing treatment options.

\begin{tabular}{|c|c|c|c|c|c|c|}
\hline & View & Measurement & Formula & $\begin{array}{c}\text { Cut-off } \\
\text { Value }\end{array}$ & $\begin{array}{l}\text { Diagnostic } \\
\text { Accuracy }\end{array}$ & Condition \\
\hline $\begin{array}{c}\text { Tingart } \\
\text { Measurement }\end{array}$ & AP & $\begin{array}{c}\text { Two levels: where the } \\
\text { proximal cortices first } \\
\text { become parrallel \& } 20 \\
\text { mm distal }\end{array}$ & $\begin{array}{c}(A-B+C-D) \\
\div \\
(2)\end{array}$ & $<6$ & $\begin{array}{c}93 \% \text { sensitivity, } \\
52 \% \text { specificity, } \\
95 \% \text { negative } \\
\text { predictive value }\end{array}$ & Osteoporosis \\
\hline $\begin{array}{l}\text { Deltoid-Tuberosity } \\
\text { Index }\end{array}$ & AP with IR & $\begin{array}{l}\text { One level: just } \\
\text { proximal to the deltoid } \\
\text { tuberosity }\end{array}$ & $F \div G$ & $<1.4$ & $\begin{array}{l}88 \% \text { sensitivity, } \\
80 \% \text { specificity }\end{array}$ & $\begin{array}{l}\text { Low-Humeral } \\
\text { Bone Density }\end{array}$ \\
\hline
\end{tabular}




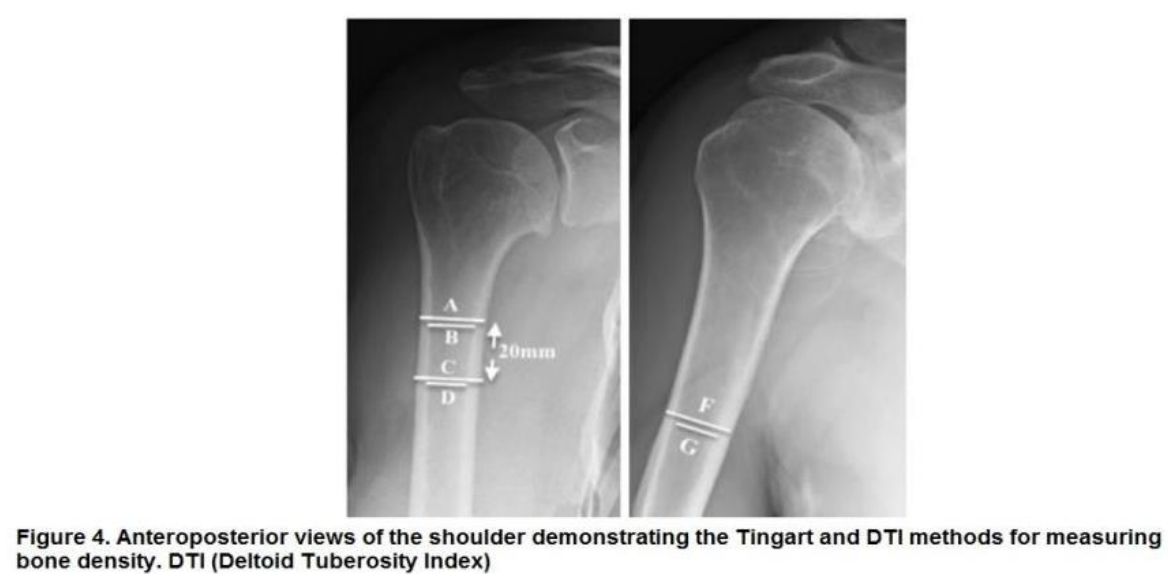

\section{Management}

Treatment of proximal humerus fractures is controversial. There is significant heterogeneity among studies, so making conclusions is difficult. In general, minimally displaced fractures, poor surgical candidates, and low demand patients are treated conservatively.

Displaced, comminuted, or angulated fractures occurring in good surgical candidates are treated with percutaneous techniques, open reduction and internal fixation or arthroplasty depending on the type of fracture pattern. Despite the risk of nonunion, symptomatic malunion or osteonecrosis, non-operative therapy even of complex proximal humerus fractures may be adequate in the very elderly or cognitive impaired population and in patients with a nonfunctional limb, well advanced drug or alcohol abuse or severe medical comorbidities [17]. These settings often require close cooperation with a geriatric physician in order to prevent secondary conditions and further falls.

\section{Minimally displaced fractures}

Around $50 \%$ to $65 \%$ of all proximal humerus fractures are minimally displaced fractures of the greater tuberosity and/or surgical neck that respond well to nonoperative management. 28, 29(p) The shoulder should be placed in a sling followed by early and adequate physiotherapy. Isometric, pendulum, or passive range of motion exercises should be started within a few days of injury. The sling can be worn until healing is evident, which usually occurs by 4 to 6 weeks. Around this time, active strengthening exercises can begin.30,31 Recently, a study by Clement et al included 211 minimally displaced proximal humerus fractures in patients aged 65 to 98 . At 1 year, the mean Constant-Murley score was 68.8 (greater than 55 was considered an acceptable outcome) ${ }^{[19]}$.

They can be closed reduced with immobilization in slight external rotation. On the other side, large, displaced fragments or fragments involving the articular surface warrant fixation.

\section{Operative treatment}

In osteoporotic bone, reduction might be difficult to obtain and yet-independent of the chosen implant-precise anatomic reduction is the cornerstone of a stable fixation and essentially enhances its longevity ${ }^{[38]}$.

Therefore, correct interpretation of the fracture pattern and its trauma mechanism is essential. Knowledge of the deforming forces of the muscular attachments helps in reducing and retaining displaced fractures. The humeral head or the articular fragment can also be pushed into a valgus deformity due to the axial load of the trauma. First and foremost, the integrity of the medial hinge-calcar must be ascertained and in case of disruption reconstructed before further reduction maneuvers are applied. The most efficient method to gain osseous medial support of the humeral bone is perfect reduction of the medial cortices. The medial periosteum plays a key role in the fracture management, because it allows indirect reduction using ligamentotaxis and it maintains the blood supply of the head fragment via branches of the posterior humeral circumflex artery. Krappinger and colleagues postulated that anatomical fracture reduction and the correct alignment of the medial cortices are the two most important prognostic factors in terms of secondary displacement $[39,40]$. Because of neighboring neurovascular structures and the insertion of rotator cuff and biceps tendons, extramedullary fixation of proximal humeral fractures mostly has to be approached from the lateral aspect ${ }^{[34,35]}$.

Therefore, reduction of the medial fracture zone can only be achieved through indirect manipulation or across the fracture line. Direct visual control is not possible. To confirm perfect reduction, fluoroscopy guidance is mandatory. Fractures with medial comminution are technically difficult or not at all manageable. In some cases, the treatment of choice then is the intended impaction of the humeral head.

Biomechanical studies could prove that even with correct axial reduction, missing calcar stabilization leads to secondary displacement with varus impaction of the humeral head ${ }^{[41]}$.

The absolute indications for the surgery are:

a) The fracture dislocation of proximal humerus.

b) Head-splitting fractures.

c) Fractures with neurovascular injuries.

\section{Two part surgical neck fractures}

In two part surgical neck fractures, the shaft is usually displaced medially and anteriorly by the pectoralis major. The deltoid pull results in overlapping of the fragments and shortening. When the distal fragment is displaced medially and superiorly, there is a high incidence of soft tissue interposition of long head of biceps that prevents reduction which warrants open stabilization. It is important to remember that the results are dependent on Antero Posterior displacement of fracture and not on surgery. Displacement upto $66 \%$ in AP view seems to be acceptable as reported by Court-Brown et al. in their recent study. Indications for surgery include displacement, polytrauma, association with other upper extremity fractures, vascular injury and open fracture. The fracture is approached anteriorly through the deltopectoral approach. Philos locking plate is the choice of fixation in osteoporotic as well as young patients ${ }^{[34]}$.

\section{Two-part isolated tuberosity fractures}

Closed reduction of two part Greater tuberosity fractures are difficult because the fragment is pulled superiorly and 
posteriorly by the attached rotator cuff muscles. This must be treated like full thickness rotator cuff tear. Hence ORIF with Philos locking plate is indicated if there is superior displacement of $5 \mathrm{~mm}$ and posterior displacement of $10 \mathrm{~mm}$. Greater tuberosity fractures are often associated with anterior dislocation of the shoulder and this should always be seen in axillary view.A deltopectoral exposure is used if there is a long inferior spike on the greater tuberosity. Exposure of the inferiormost portion of the fragment through a superior approach could damage the axillary nerve. When exposing the greater tuberosity through a deltopectoral incision, posterior exposure is greatly facilitated by abduction of the arm to relax the deltoid muscle ${ }^{[34]}$.

\section{Three \& four part fractures}

These fractures are more complex and are major orthopedic challenge - the decision is mainly based on the age, comorbidities, comminution, head split, fracture dislocations and activity level of the patient. The main decision in elderly is fixation or replacement. Four part displaced fractures, four part fracture dislocations, impression fractures of the articular surface involving more than $40 \%$ of the head and headsplitting fractures are best treated by primary prosthetic replacement ${ }^{[34]}$.

Surgical technique: Surgery is performed under brachial block with patient in supine position and the shoulders on radiolucent support at the edge of the table. The shoulder is exposed through the deltopectoral approach and this forms the workhorse approach to the joint. Care must be exercised that the dissection is lateral to coracoid process. Identifying Cephalic vein and preserving it should be always kept in the mind. Its important to stay lateral to bicipital groove so that the arcuate artery is not disturbed. At this stage, the arm must be completely abducted continuously so that the deltoid remains in lax position and retraction is easier. Pectoralis insertion is a good landmark as its proximal edge indicates the level of axillary nerve ${ }^{[34]}$.

The reduction is secured with $\mathrm{K}$-wires and later stabilized with locking plate and screws depending on the fracture pattern and bone quality. It is very important to get the calcar screw in plate as it reduces the varus collapse. (Figure 5)

Gardner et al. suggested obliquely positioned inferomedial screws as an additive support tool. A calcar screw reduces the risk of a varus collapse with subsequent screw perforation by counteracting the varus deforming forces acting on the humeral head. This results in a significantly higher reposition stability after 6 and 12 months [39,40]. With new minimally invasive techniques, the need for calcar screws often has been questioned. However, the positive clinical impact of calcar screws in terms of complication rate, fracture reduction, and Constant score has been repeatedly shown, especially for more complex fractures. In order not to harm the axillary nerve in minimal invasive plate osteosynthesis, the insertion of calcar screws should only be performed under direct vision [41]. The insertion of calcar screws does not increase the risk of humeral head necrosis by compromising the medial periosteal blood supply. Insertion of more than one calcar screw does not provide additional torsional or axial stability [41].

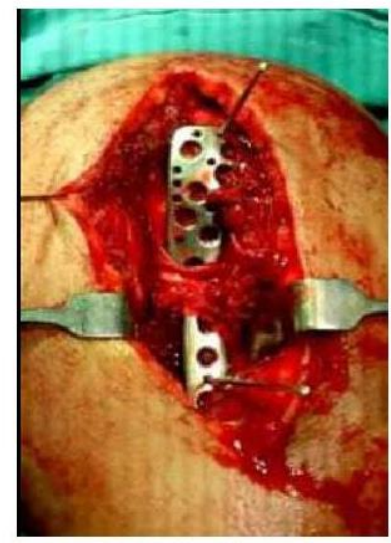

Intra-op image depicting the axillary nerve and the PHILOS plate being slid underneath it.

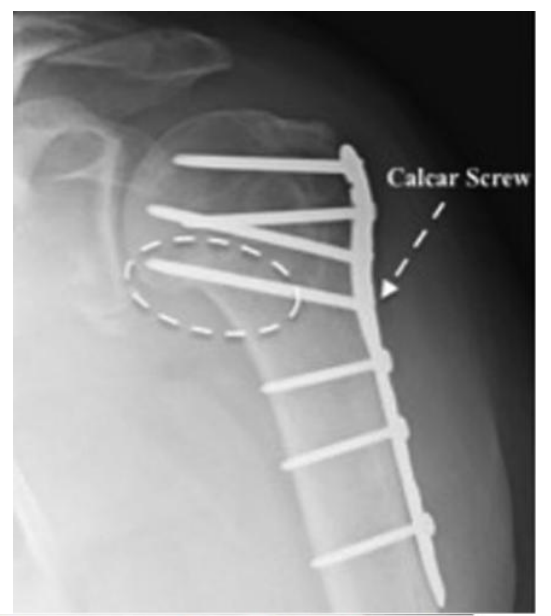

Figure5. Postoperative AP view of a 3-part fracture treated with a locking plate. Note the screw traversing the inferomedial humeral head, which is important for providing a medial support in the calcar region (dotted circle). With significant medial bone loss, graft material, fibular struts, or cement can be used to augment the construct. Tuberosities can be captured with screws or sutured to the plate.

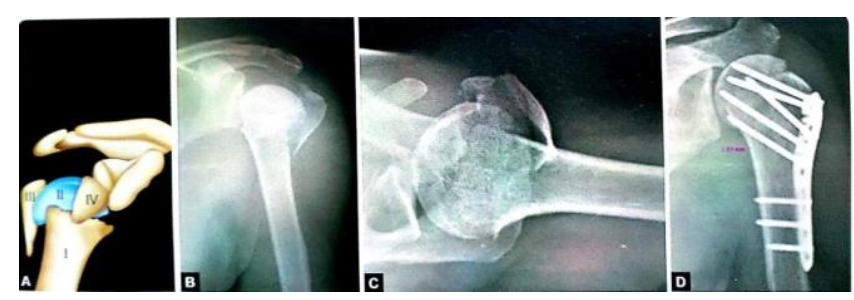

Fig: Valgus impacted proximal humerus four part fracture managed with philos-locking plate with good result

\section{Surgical hardware- philos plate system construct}

\begin{tabular}{|c|c|c|}
\hline \multicolumn{2}{|c|}{ Screws used with PHILOS } & \multirow[b]{2}{*}{ 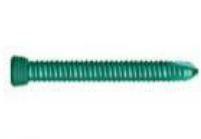 } \\
\hline - X12.102-124 & $\begin{array}{l}\text { Locking Screw Stardrive } \varnothing 3.5 \mathrm{~mm} \text {, } \\
\text { length } 12-60 \mathrm{~mm} \text {, } \\
\text { self-tapping }\end{array}$ & \\
\hline - X13.012-060 & $\begin{array}{l}\text { Locking } S c r e w \varnothing 3.5 \mathrm{~mm} \text {, } \\
\text { length } 12-60 \mathrm{~mm} \text {, self-tapping, } \\
\text { with hexagonal recess }\end{array}$ & 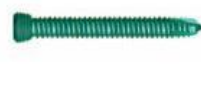 \\
\hline - X04.814-860 & $\begin{array}{l}\text { Cortex Screw } \varnothing 3.5 \mathrm{~mm} \text {, } \\
\text { length } 12-60 \mathrm{~mm} \text {, self-tapping, } \\
\text { with hexagonal recess }\end{array}$ & Ontmant \\
\hline $\begin{array}{l}\text { - Stardrive } \\
\text { - Hexagonal }\end{array}$ & & \\
\hline
\end{tabular}


PHILOS Proximal Humeral Internal

Locking System

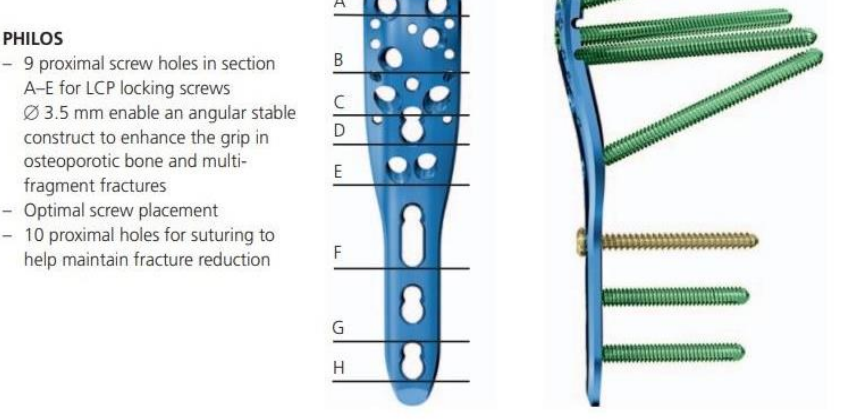

\section{Conclusion}

The treatment of proximal humerus fractures still remains challenging. The majority of proximal humerus fractures are nondisplaced by Neer's criteria. The results of surgical management of displaced fractures are variable and dependent on fracture type, bone quality, quality of the surgical reduction and fixation, surgeon experience, and patient compliance ${ }^{[34]}$. When the decision for surgical fixation is made, anatomic reduction with restoration of medial support and protection of vascular and periosteal structures are crucial prognostic factors and the most reliable feature in the prevention of secondary varus dislocation.

Philos plate provides stable fixation in proximal humerus fractures. Additionally, meticulous surgical dissection to preserve vascularity of humeral head is necessary to prevent potential complications such as AVN. As majority of these fractures occur in the osteoporotic bone, the operative treatment with Philos plate has of now become the gold standard.

In geriatric patients, nonoperative management can also produce a high percentage of acceptable results, provided that rehabilitation exercises are instituted within 2 weeks of injury. A close cooperation with a geriatric physician is recommended for the purpose of early active rehabilitation and to prevent secondary conditions.

\section{Disclosure}

The author reports no conflicts of interest in this work.

\section{References}

1. Court-Brown CM, Caesar B. Epidemiology of adult fractures: a review. Injury. 2006; 37(8):691-697. doi:10.1016/j.injury.2006.04.130.

2. Calvo E, Morcillo D, Foruria AM, Redondo-Santamarı'a E, Osorio-Picorne F, Caeiro JR. Nondisplaced proximal humeral fractures: high incidence among outpatienttreated osteoporotic fractures and severe impact on upper extremity function and patient subjective health perception. J Shoulder Elbow Surg. 2011; 20(5):795-801. doi:10.1016/j.jse.2010.09.008.

3. Palvanen M, Kannus P, Niemi S, Parkkari J. Update in the epidemiology of proximal humeral fractures. Clin Orthop. 2006; 442:87-92.

4. Savin DD, Zamfirova I, Iannotti J, Goldberg BA, Youderian AR. Survey study suggests that reverse total shoulder arthroplasty is becoming the treatment of choice for four-part fractures of the humeral head in the elderly. Int Orthop. 2016; 40(9):1919-1925. Doi:10.1007/s00264016-3227-y.
5. Okike K, Lee OC, Makanji H, Harris MB, Vrahas MS. Factors associated with the decision for operative versus non-operative treatment of displaced proximal humerus fractures in the elderly. Injury. 2013; 44(4):448-455. doi:10.1016/j.injury.2012.09.002.

6. McLaurin TM. Proximal humerus fractures in the elderly are we operating on too many? Bull Hosp Jt Dis N Y N. 2004;62(1-2):24-32.

7. Handoll HHG, Ollivere BJ, Rollins KE. Interventions for treating proximal humeral fractures in adults. Cochrane Database Syst Rev. 2012; 12:CD000434. doi:10.1002/14651858.CD000434.pub3.

8. Handoll HH, Keding A, Corbacho B, Brealey SD, Hewitt C, Rangan A. Five-year follow-up results of the PROFHER trial comparing operative and non-operative treatment of adults with a displaced fracture of the proximal humerus. Bone Joint J. 2017; 99-B(3):383-392. doi:10.1302/0301-620X.99B3.BJJ-2016-1028.

9. Boileau P, Walch G. The three-dimensional geometry of the proximal humerus. J Bone Joint Surg Br. 1997; 79$\mathrm{B}(5): 857-865$.

10. Murachovsky J, Ikemoto RY, Nascimento LGP, Fujiki EN, Milani C, Warner JJP. Pectoralis major tendon reference (PMT): a new method for accurate restoration of humeral length with hemiarthroplasty for fracture. J Shoulder Elbow Surg. 2006; 15(6):675-678. doi:10.1016/j.jse.2005.12.011.

11. Rockwood CA ed. The Shoulder. 4th ed. Philadelphia, PA: Saunders/Elsevier, 2009.

12. Hertel R, Hempfing A, Stiehler M, Leunig M. Predictors of humeral head ischemia after intracapsular fracture of the proximal humerus. J Shoulder Elbow Surg. 2004; 13(4):427-433. doi:10.1016/S1058274604000795.

13. Thorsness R, English C, Gross J, Tyler W, Voloshin I, Gorczyca J. Proximal humerus fractures with associated axillary artery injury. J Orthop Trauma. 2014; 28(11):659-663. doi:10.1097/BOT.

14. 0000000000000114.

15. Visser CP, Coene LN, Brand R, Tavy DL. Nerve lesions in proximal humeral fractures. J Shoulder Elbow Surg. 2001; 10(5):421-427. doi:10.1067/mse.2001.118002.

16. Bono CM, Grossman MG, Hochwald N, Tornetta P. Radial and axillary nerves. Anatomic considerations for humeral fixation. Clin Orthop. 2000; (373):259-264.

17. Ninck J, Heck S, Gick S, Koebke J, Pennig D, Dargel J. Treatment of proximal humerus fractures: relative position of different locking plates to the axillary nerve. Unfallchirurg. 2013; 116(11):1000-1005. Doi: 10.1007/s00113-012-2242-8.

18. Carofino BC, Leopold SS. Classifications in brief: the Neer classification for proximal humerus fractures. Clin Orthop. 2013; 471(1):39-43. Doi: 10.1007/s11999-0122454-9.

19. Gallo RA, Sciulli R, Daffner RH, Altman DT, Altman GT. Defining the relationship between rotator cuff injury and proximal humerus fractures. Clin Orthop. 2007; 458:70-77. doi:10.1097/BLO.0b013e31803bb400.

20. Clement ND, Duckworth AD, McQueen MM, CourtBrown CM. The outcome of proximal humeral fractures in the elderly: predictors of mortality and function. Bone Joint J. 2014; 96-B(7):970-977. doi:10.1302/0301620X.96B7.32894.

21. Fjalestad T, Hole MØ, Blu“cher J, Hovden IAH, Stiris MG, Strømsøe K. Rotator cuff tears in proximal humeral fractures: an MRI cohort study in 76 patients. Arch 
Orthop Trauma Surg. 2010; 130(5):575-581. doi:10.1007/s00402-009-0953-2.

22. Spross C, Zeledon R, Zdravkovic V, Jost B. How bone quality may influence intraoperative and early postoperative problems after angular stable open reduction-internal fixation of proximal humeral fractures. J Shoulder Elbow Surg. 2017; 26(9):1566-1572. doi:10.1016/j.jse.2017.02.026.

23. Jung S-W, Shim S-B, Kim H-M, Lee J-H, Lim H-S. Factors that influence reduction loss in proximal humerus fracture surgery. J Orthop Trauma. 2015; 29(6):276-282. Doi:10.1097/BOT. 0000000000000252.

24. Mather J, MacDermid JC, Faber KJ, Athwal GS. Proximal humerus cortical bone thickness correlates with bone mineral density and can clinically rule out osteoporosis. J Shoulder Elbow Surg. 2013; 22(6):732738. doi:10.1016/j.jse.2012.08.018.

25. Spross C, Kaestle N, Benninger E et al. Deltoid tuberosity index: a simple radiographic tool to assess local bone quality in proximal humerus fractures. Clin Orthop. 2015; 473(9):3038-3045. Doi:10. 1007/s11999015-4322-x.

26. Grawe B, Le T, Lee T, Wyrick J. Open reduction and internal fixation (ORIF) of complex 3- and 4-part fractures of the proximal humerus: does age really matter? Geriatr Orthop Surg Rehabil. 2012; 3(1):27-32. Doi:10.1177/2151458511430662.

27. Hinds RM, Garner MR, Tran WH, Lazaro LE, Dines JS, Lorich DG. Geriatric proximal humeral fracture patients show similar clinical outcomes to non-geriatric patients after osteosynthesis with endosteal fibular strut allograft augmentation. J Shoulder Elbow Surg. 2015; 24(6):889896. doi:10.1016/j.jse. 2014.10.019.

28. Goch AM, Christiano A, Konda SR, Leucht P, Egol KA. Operative repair of proximal humerus fractures in septuagenarians and octogenarians: does chronologic age matter? J Clin Orthop Trauma. 2017; 8(1):50-53. doi:10.1016/j.jcot.2017.01.006.

29. Bergdahl C, Ekholm C, Wennergren D, Nilsson F, Mo“ller M. Epidemiology and patho-anatomical pattern of 2,011 humeral fractures: data from the Swedish Fracture Register. BMC Musculoskelet Disord. 2016; 17:159. Doi:10.1186/s12891-016-1009-8.

30. Court-Brown CM, Garg A, McQueen MM. The epidemiology of proximal humeral fractures. Acta Orthop Scand. 2001; 72(4):365-371.

Doi:10.1080/000164701753542023.

31. Lill H, Ellwein A, Katthagen C, Voigt C. Osteoporotische Frakturen am proximalen humerus. Chirurg. 2012; 83(10):858-865. Doi:10.1007/s00104012-2337-3.

32. Koval KJ, Gallagher MA, Marsicano JG, Cuomo F, McShinawy A, Zuckerman JD. Functional outcome after minimally displaced fractures of the proximal part of the humerus. J Bone Joint Surg Am. 1997; 79(2):203-207.

33. Chun J-M, Groh GI, Rockwood CA. Two-part fractures of the proximal humerus. J Shoulder Elbow Surg. 1994; 3(5):273-287. Doi: 10.1016/S1058-2746(09)80071-2.

34. Tamimi I, Montesa G, Collado F et al. Displaced proximal humeral fractures: when is surgery necessary? Injury. 2015; 46(10):1921-1929. doi:10.1016/j.injury.2015.05.049.

35. Dheenadhayalan J. Textbook of Orthopedics and Trauma. Edn 3, Jaypee the health sciences publisher, India, 2016; 2:1381-1393.
36. Eid A, Osman M, Fekry H-E. Percutaneous fixation with Schanz screws for displaced two- and three- part fractures of the proximal humerus in patients above fifty years of age. Int J Shoulder Surg. 2011; 5(2):38-43. doi:10.4103/0973-6042.83195.

37. Vundelinckx BJ, Dierickx CA, Bruckers L, Dierickx CH. Functional and radiographic medium-term outcome evaluation of the humerus block, a minimally invasive operative technique for proximal humeral fractures. J Shoulder Elbow Surg. 2012; 21(9):1197-1206. doi:10.1016/j.jse.2011.07.029.

38. Bogner R, Hu“bner C, Matis N, Auffarth A, Lederer S, Resch H. Minimally-invasive treatment of three- and four-part fractures of the proximal humerus in elderly patients. J Bone Joint Surg Br. 2008; 90(12):1602-1607. doi:10.1302/0301-620X.90B12.20269.

39. Dilisio MF, Nowinski RJ, Hatzidakis AM, Fehringer EV. Intramedullary nailing of the proximal humerus: evolution, technique, and results. J Shoulder Elbow Surg. 2016; 25(5):e130-e138. doi: 10.1016/j.jse.2015.11.016.

40. Lopiz Y, Garcia-Coiradas J, Garcia-Fernandez C, Marco F. Proximal humerus nailing: a randomized clinical trial between curvilinear and straight nails. J Shoulder Elbow Surg. 2014; 23(3):369-376. doi:10.1016/j.jse.2013.08.023.

41. Nolan BM, Kippe MA, Wiater JM, Nowinski GP. Surgical treatment of displaced proximal humerus fractures with a short intramedullary nail. J Shoulder Elbow Surg. 2011; 20(8):1241-1247.

42. Katthagen JC, Schwarze M, Meyer-Kobbe J, Voigt C, Hurschler C, Lill H. Biomechanical effects of calcar screws and bone block augmentation on medial support in locked plating of proximal humeral fractures. Clin Biomech. 2014; 29:735-41. 